\title{
Ecotourism Quality Attributes and Competitive Strategies
}

\author{
Yu-Min Wei ${ }^{\text {a }}$, Sang-Bing Tsai ${ }^{b c^{*}}$ \\ ${ }^{a}$ College of Tourism and Service Management, Nankai University, Tianjin 300071, China \\ ${ }^{\mathrm{b}}$ Law School, Nankai University, Tianjin 300071, China \\ ${ }^{\mathrm{c}}$ Zhongshan Institute, University of Electronic Science and Technology of China, Guangdong \\ 528402, China \\ *Corresponding author: Sang-Bing Tsai, Prof. sangbing@hotmail.com
}

\begin{abstract}
Ecotourism is currently at an early stage of development. How to design ecotourism products that satisfy consumer needs and ensure environmental sustainability warrants investigation. In this study, an importance-performance analysis was conducted to identify factors affecting customer satisfaction regarding ecotourism. The findings of this study are expected to inform the development of low-carbon tourism products and facilitate the obtainment of the resources required to improve key quality attributes.
\end{abstract}

Key words: ecotourism; quality attribute; importance-performance analysis model; competitive strategy; performance

\section{Introduction}

The growing incidence of natural disasters worldwide caused by weather anomalies is prompting people to engage in environmental protection, energy conservation, and carbon reduction. Green consumption and green industries have received global attention, and people are increasingly adopting environmentally friendly actions such as waste separation and using reusable utensils and shopping bags. Travel behavior has also changed; bicycle tourism and ecotourism are among the emerging forms of travel behavior.

As their financial capabilities improve, people become increasingly engaged in travel. However, growing participation in tourism contributes to traffic, food consumption, accommodation use, and energy-related emissions. A report released by the World Economic Forum suggested that tourism industries, including tourism-related transportation industries, cumulatively account for $5 \%$ of global carbon emissions (with $2 \%$ and $3 \%$ of global emissions attributable to transportation and tourism industries, respectively) ${ }^{1}$ (Simpson et al., 
2008). Clearly, travel agencies and travelers are contributors to global warming; travel and tourism accounts for $9.2 \%$ of global GDP and is forecast to rise to $9.5 \%$ by $2020^{2}$. As demand for travel increases, ecotourism should be promoted for the sake of environmental protection. Ecotourism is currently at an early stage of development, receiving limited investment from public and private sectors. To realize the market potential for the products of this under-resourced industry, product quality attributes affecting customer satisfaction can be identified and enhanced. This study reviewed ecotourism literature to identify quality attributes affecting customer satisfaction in ecotourism, analyzing competitive strategies adopted by ecotourism operators and contributing to the development of ecotourism products.

\section{Literature Review}

Recreational tourism is often regarded as having little impact on the environment. However, increasing participation in recreational tourism by the general public is causing harm to tourist destinations (i.e., is being associated with conditions such as inappropriate tourist behavior, excessive use, and improper activity sites), disturbing and even endangering local environments, cultures, and economies ${ }^{3}$.

Ecotourism refers to a form of tourism in which travel agencies, tour guides, hotels, and tourist destination managers participate in natural conservation and environmental protection ${ }^{4}$. On an ecotour, travelers engage in not only sightseeing or entertainment activities but also in environmentally friendly practices to raise their environmental awareness. Thea ${ }^{5}$ referred to ecotourism as an economic development model that employs resources and environments on basis of the principles of reduce, reuse, and recycle to achieve a high efficiency of resource utilization and minimize environmental damage. Thus, ecotourism consumers can undertake green practices to learn about and immerse themselves in the natural world.

Simpson et al. ${ }^{1}$ perceived ecotourism as a low-carbon lifestyle at the personal level and proposed three approaches to encouraging its adoption among travelers:

(1) Changing the existing travel model to promote the use of public transportation and lowand zero-carbon vehicles (e.g., hybrid cars, electric cars, and bicycles), thereby enabling the creation of further travel products and enriching travel experiences.

(2) Replacing luxury tours with less extravagant but sufficiently clean, convenient, and comfortable tours to enhance a brand of destinations. 
(3) Improving tourism in a technological fashion to streamline operations in the industry and integrate energy-conservation and carbon-reduction technologies, thereby creating a circular economic model for the supply chain of the industry.

The following low-carbon measures can be implemented in tourism-related industries to enrich ecotourism experiences ${ }^{2}$ :

(1) Travel agencies can integrate low-carbon tours and carbon footprint calculation into their product portfolios to involve their customers in low-carbon consumption.

(2) Hotel operators can build environmentally friendly lodging establishments or green their existing facilities to involve their customers in green consumption. Solar power systems and energy-efficient appliances can be used; management approaches can be improved in ways that ensure environmental wellbeing.

(3) Scenic areas can be managed with further utilization of existent local resources but less development to promote low-carbon travel (e.g., using trash containers made of rattan instead of plastic to improve environmental wellbeing and compliment the scenery).

This study proposed 10 quality attributes to measure the ecotourism quality performance of a travel agency. These 10 quality attributes are detailed in Table 1.

\section{Method}

\subsection{Importance-Performance Analysis}

Martilla and James ${ }^{6}$ proposed and applied the framework of importance-performance analysis (IPA). In IPA, the mean values for importance and performance attributes are displayed on a two-dimensional grid, with importance on the $\mathrm{y}$ axis and performance on the $\mathrm{x}$ axis (Fig. $1)^{7-13}$.

The importance-performance matrix comprises four quadrants ${ }^{14-17}$ :

(1) Keep Up the Good Work: Attributes that consumers regard as highly important and in which the enterprise has shown highly satisfactory performance.

(2) Concentrate Here: Attributes that consumers regard as highly important but in which the enterprise has shown inadequate satisfactory performance.

(3) Low Priority: Attributes that consumers regard as of low importance and in which the enterprise has shown inadequate satisfactory performance.

(4) Possible Overkill: Attributes that consumers regard as of low importance but in which the enterprise has shown highly satisfactory performance.

By applying this four-quadrant matrix, managers can make the most effective possible use of limited resources and prioritize criteria for improvement to increase customer satisfaction. 
The IPA has been applied in numerous fields to measure attribute quality and prioritize attributes for improvement in meeting consumer demands ${ }^{18-20}$.

\subsection{Case Study}

This study evaluated the ecotourism quality performance of Company $\mathrm{X}$, the second-largest travel agency in Taiwan, and provided recommendations for improvement regarding the company's ecotourism products.

A 7-point Likert scale comprising 10 items was administered to 320 customers of Company X from March 1-April 15, 2016. A total of 265 valid responses were retrieved, with a valid return rate of $82.81 \%$.

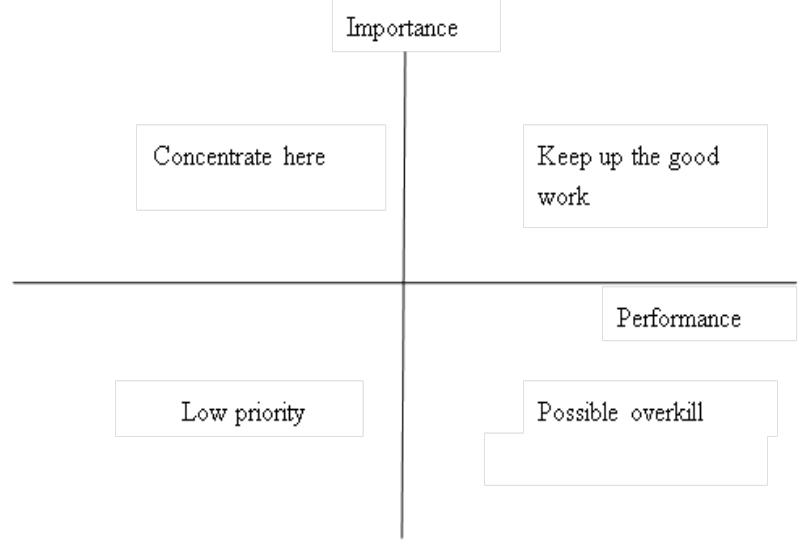

Fig. 1 - Importance-performance matrix.

\section{Results and Discussion}

The average importance score (5.83) and performance score (5.75) were used as baselines to determine whether the performance of each quality attribute was "good" or "poor" (Table 1). Based on the IPA results, Quality Attributes 4 “using ‘ecotourism’ as an advertising slogan”, 6 "not disturbing the local ecology during tours", 7 "no environmental damage caused by tour guides during tours", and 9 "tour guides and local residents are committed to preserving local environments” were located in the "Keep Up the Good Work” quadrant. These attributes were considered as the strengths that Company $\mathrm{X}$ should maintain to sustain product quality and boost the popularity of its ecotourism products.

Quality Attributes 2 "local cuisines are prepared with locally-sourced ingredients”, 5 "green concepts integrated into local tourism seasons or events", and 10 "affording opportunities to experience local cultures" fell into the "Concentrate Here" quadrant. Company X should divert their resources to focus on improving their performance regarding these three quality attributes to enhance its competitiveness. 
Furthermore, Quality Attributes 1 "public transportation or shuttle buses are used to meet tourist travel arrangements" and 8 "tour guides encourage tourists to do as the locals do" were located in the "Low Priority" quadrant. For Company X, these attributes evidenced poor performance and importance and can be improved when additional resources are available. Finally, Quality Attribute 3 “tour guides describe local ecological and cultural environments in a detailed and professional manner”, which had low importance but good performance, fell into the "Possible Overkill” quadrant. This indicated that, despite its good performance, this attribute contributed no value to the performance of Company $\mathrm{X}$, and resources invested in the attribute should be diverted to other attributes.

Table 1 - Importance and performance values of ecotourism quality attributes.

\begin{tabular}{|c|c|c|c|c|}
\hline Item No. & Quality Attribute & Importance & Performance & $\begin{array}{l}\text { Competitive } \\
\text { Strategy }\end{array}$ \\
\hline 1 & $\begin{array}{l}\text { Public transportation or shuttle buses are used to } \\
\text { meet tourist travel arrangements }\end{array}$ & 5.3 & 5.5 & Low priority \\
\hline 2 & $\begin{array}{l}\text { Local cuisines are prepared with locally-sourced } \\
\text { ingredients }\end{array}$ & 5.9 & 5.3 & $\begin{array}{l}\text { Concentrate } \\
\text { here }\end{array}$ \\
\hline 3 & $\begin{array}{l}\text { Tour guides describe local ecological and cultural } \\
\text { environments in a detailed and professional manner }\end{array}$ & 5.3 & 5.9 & $\begin{array}{l}\text { Possible } \\
\text { overkill }\end{array}$ \\
\hline 4 & Using "ecotourism" as an advertising slogan & 6.1 & 6.2 & $\begin{array}{l}\text { Keep up the } \\
\text { good work }\end{array}$ \\
\hline 5 & $\begin{array}{l}\text { Green concepts integrated into local tourism seasons } \\
\text { or events }\end{array}$ & 6.2 & 5.6 & $\begin{array}{l}\text { Concentrate } \\
\text { here }\end{array}$ \\
\hline 6 & Not disturbing the local ecology during tours & 6.0 & 5.9 & $\begin{array}{l}\text { Keep up the } \\
\text { good work }\end{array}$ \\
\hline 7 & $\begin{array}{l}\text { No environmental damage caused by tour guides } \\
\text { during tours }\end{array}$ & 6.1 & 6.0 & $\begin{array}{l}\text { Keep up the } \\
\text { good work }\end{array}$ \\
\hline 8 & Tour guides encourages tourists to do as the locals do & 5.5 & 5.6 & Low priority \\
\hline 9 & $\begin{array}{l}\text { Tour guides and local residents are committed to } \\
\text { preserving local environments }\end{array}$ & 5.9 & 5.9 & $\begin{array}{l}\text { Keep up the } \\
\text { good work }\end{array}$ \\
\hline 10 & Affording opportunities to explore local cultures & 6.0 & 5.6 & $\begin{array}{l}\text { Concentrate } \\
\text { here }\end{array}$ \\
\hline Mean & & 5.83 & 5.75 & \\
\hline
\end{tabular}

\section{Conclusion}

Ecotourism is a form of tourism that produces minimal environmental impact, encouraging participation in energy conservation and carbon reduction and facilitating immersion in local ecological and cultural landscapes. In other words, ecotourism not only provides an in-depth view of the natural and cultural characteristics of tourist destinations, but also highlights the need to minimize disturbance to local ecologies and reduce carbon emissions during tours.

This study measured the ecotourism quality performance of Company $\mathrm{X}$ on the basis of 10 quality attributes and provided recommendations for improvement to the travel agency's 
ecotourism products. The IPA results showed that Quality Attributes 4, 6, 7, and 9 represented the competitive strengths that Company X should maintain. However, Quality Attributes 2, 5, and 10 represented the weaknesses that the company should focus on improving to enhance its competiveness.

\section{References:}

1. Simpson, M.C., Gössling, S., Scott, D., Hall, C.M. \& Gladin, E, 2008. Climate Change Adaptation and Mitigation in the Tourism Sector: Frameworks, Tools and Practices, UNEP, University of Oxford, UNWTO, WMO: Paris, France.

2. Tsai, S. B., Lee, Y. C., Wu, C. H. \& Guo, J. J. 2013. Examining How Manufacturing Corporations Win Orders. South African Journal of Industrial Engineering. 24(3): 112-124.

3. Smith, L.J. 1994. The tourism product. Annals of Tourism Research, 21(3), 582-593.

4. Tan, K.C. \& Pawitra, T.A. 2001. Integrating SERVQUAL and Kano's Model into QFD for Service Excellence Ddevelopment, Managing Service Quality, 11(6), 418-430.

5. Thea, Chiesa. 2009. Towards a Low Carbon Travel \& Tourism Sector, Head Aviation, Travel \& Tourism, World Economic Forum.

6. Martilla, J. A. \& James, J. C. 1977. Importance-Performance Analysis. Journal of Marketing, 41 (1), 77-79.

7. Lee, Y.C., Chen, C.Y., Tsai, S.B. \& Wang, C.T. 2014. Discussing green environmental performance and competitive strategies. Pensee 76 (7), 190-198.

8. Guo, W.F., Zhou, J., Yu, C.L., Tsai, S.B., et al. 2015. Evaluating the green corporate social responsibility of manufacturing corporations from a green industry law perspective. International Journal of Production Research 53 (2), 665-674.

9. Tsai, S. B., Chien M.F., Xue Y, Li L., et al. 2015a. Using the Fuzzy DEMATEL to determine Environmental Performance: A Case of Printed Circuit Board Industry in Taiwan. Plos One 10(6): e0129153. doi:10.1371/journal.pone.0129153.

10. Tsai, S. B., Saito, R., Lin, Y. C., Chen, Q., et al. 2015b. Discussing measurement criteria and competitive strategies of green suppliers from a Green law Perspective. Proceedings of the Institution of Mechanical Engineers. Proceedings of the Institution of Mechanical Engineers, Part B: Journal of Engineering Manufacture 229(S1): 135-145. 
11. Lee, Y.C., Wu, C.H. \& Tsai, S.B. 2014. Grey System Theory and Fuzzy Time Series Forecasting for the Growth of Green Electronic Materials. International Journal of Production Research, 299(8), 1395-1406.

12. Guo, J.J. \& Tsai, S.B. 2015. Discussing and evaluating green supply chain suppliers: A case study of the printed circuit board industry in China. South African Journal of Industrial Engineering 26 (2), 56-67.

13. Tsai, S. B., Xue, Y., Huang, P. Y., et al. 2015. Establishing a criteria system for green production. Proceedings of the Institution of Mechanical Engineers, Part B: Journal of Engineering Manufacture 229(8): 1395-1406.

14. Tsai, S.B., Huang, C.Y., Wang, C.K., Chen, Q., et al. 2016. Using a Mixed Model to Evaluate Job Satisfaction in High-Tech Industries. Plos One, 11(5): e0154071. doi:10.1371/journal.pone.0154071

15. Tsai, S.B. 2016. Using Grey Models for Forecasting China's Growth Trends in Renewable Energy Consumption. Clean Technologies and Environmental Policy, 18, 563-571.

16. Tsai, S.B., Lee, Y.C. and Guo, J.J. 2014. Using Modified Grey Forecasting Models to Forecast the Growth Trends of Green Materials. Proceedings of the Institution of Mechanical Engineers, Part B: Journal of Engineering Manufacture, 228(6), 931-940.

17. Zhou, J. Wang, Q., Tsai, S.B., et al. 2016. How to Evaluate the Job Satisfaction of Development Personnel. IEEE Transactions On Systems Man Cybernetics-Systems. 10.1109/TSMC.2016.2519860.

18. Guo, J.J. and Tsai, S.B. 2015. Discussing and Evaluating Green Supply Chain Suppliers: A Case Study of the Printed Circuit Board Industry in China. South African Journal of Industrial Engineering, 26(2), 56-67.

19. Su, J.M., Lee, S.C., Tsai, S.B., et al. 2016. A Comprehensive Survey of the Relationship between Self-efficacy and Performance for the Governmental Auditors. SpringerPlus, 5:508. DOI: 10.1186/s40064-016-2104-X.

20. Qu, Q., Chen, K.Y., Wei, Y.M., et al. 2015. Using Hybrid Model to Evaluate Performance of Innovation and Technology Professionals in Marine Logistics Industry Mathematical Problems in Engineering, Article ID 361275, 8 pages, http://dx.doi.org/10.1155/2015/361275. 